\title{
The Transpacific-Partnership.
}

\section{A quest for a Twenty-first-Century}

\section{Trade Agreement}

C.L. Lim, Deborah K. Elms y Patrick Low.

Cambridge University Press, 2012, 337 pp.

El libro aborda las negociaciones del Trans-Pacific Partnership (TPP), que reúne a 12 países de América, Asia y Oceanía ${ }^{1}$, iniciadas en marzo de 2010 y que a fines de julio de 2012 se encontraban en su $18^{a}$ Ronda. Éste eventual Acuerdo Comercial Regional (ACR) reuniría al 40\% del PIB mundial², cifra impresionante que en realidad se explicaría básicamente por la presencia de Estados Unidos y en menor medida de Japón, presenta características bastante complejas, por la diversidad tanto geográfica como de grados de desarrollo económico de los países involucrados, porque ha ido incorporando en las conversaciones a nuevos integrantes y porque se propone alcanzar compromisos de gran profundidad.

La suma de estos elementos haría que estuviésemos en presencia de Un acuerdo del siglo XXI. Es lo que se preguntan C.L. Lim, de la Universidad de Hong-Kong, Deborah K. Elms, de la Tamasek Foundation Centre for Trade \& Negotiations de Singapur y Patrick Low, de la Organización Mundial del Comercio (OMC), editores de esta obra compuesta de 20 capítulos escritos por 16 autores provenientes de universidades, centros de estudio y organismos internacionales como

1 Australia, Brunei Darussalam, Canadá, Chile, Estados Unidos,, Japón, Malasia, México, Nueva Zelandia, Perú, Singapur y Vietnam.

2 Básicamente aportado por Estados Unidos y Japón. 
la OMC y la CEPAL, que se ocupan de estos temas. El libro está estructurado en tres partes: » The past: origins of the TPP Agreement ", » The present: twenty-first century elements and obstacles « y »The future: high quality meets regional and global realities «.

A lo largo de cinco capítulos, la primera de ellas ofrece un panorama de los principales lineamientos de las negociaciones realizadas hasta 2012, excluida la incorporación oficial de los últimos tres países, México y Canadá a fines de año, y Japón, en julio de $2013^{3}$. Asimismo, contiene una detallada reseña de la forma que estaría adquiriendo el TPP, que si bien originalmente partiría de la base del Transpacific Strategic Económic Partnership (P-4), en realidad estaría negociando un acuerdo nuevo y no una simple ampliación del acuerdo entre Chile, Nueva Zelandia, Singapur y Brunei Darussalam. Plantea dilemas como la incógnita de lo que ocurrirá con los ACR existentes, preguntándose si serán reemplazados o existirán paralelamente, duda que también surge respecto de lo que ocurrirá con compromisos ya negociados.

En la segunda parte, »The present: twenty-first century elements and obstacles «, se detallan a lo largo de nueve capítulos una serie de aspectos específicos presentes de las negociaciones, como el problema de la incorporación de las reglas de origen, asunto bastante en especial porque se trata de cómo integrar cerca de 30 ACR existentes que involucran a los 12 países negociadores. Asimismo, se exploran puntos bastante problemáticos, como el caso de las negociaciones en materia de protección de los derechos de propiedad intelectual o de las inversiones.

La tercera parte del libro, »The future: high quality meets regional and global realities «, analiza el componente más bien político que rodea a las negociaciones del TPP. En ella aparece como tema central el papel de Estados Unidos en las negociaciones del acuerdo, en que el TPP aparece como la vía impulsada por ese país para crear un área de libre comercio en el marco del APEC, en contraposición a otros proyectos que perseguirían objetivos análogos, como sería el caso de los ACR en el marco de las ampliación de la Asociación de

»Statement on the 18th Round of Trans-Pacific Partnership Negotiations «, Office of the United States Representative, www.ustr. gov/tpp 
Naciones del Sudeste Asiático (ASEAN), alternativa impulsada por China, que es quizá la gran ausente de estas negociaciones.

De lo anterior se desprende que, en realidad, las negociaciones del TPP se insertarían dentro de un proyecto más amplio que el estrictamente comercial, como serían los intereses estadounidenses de largo plazo en un área clave para ese país como el Asia-Pacífico, argumento muy bien explicitado por Ann Capling y John Ravenhill (» The TPP: multilateralizing regionalismo or the securitization of trade policy «). La presencia de Estados Unidos en el TPP es quizá el gran tema transversal del libro, cuya lectura lleva a preguntarse si estamos realmente en presencia de negociaciones entre 12 países o se trata más bien de 11 países que intentan acoplarse a un ACR planteado en los términos estadounidenses. La no inclusión de China en el TPP y la presencia en paralelo de las negociaciones del acuerdo Regional Comprehensive Economic Partnership (ASEAN+6), iniciativa de las naciones de la Asociación de Naciones del Sudeste Asiático (ASEAN) con seis importantes países de la región, incluyendo a la segunda economía del mundo ${ }^{4}$, lleva a pensar que en realidad el TPP responde principalmente a los intereses de largo plazo de Estados Unidos en el Asia-Pacífico.

La observación anterior obedece a que Estados Unidos es el único país al que se dedica un capítulo específico (»US PTA's: what's been done and what it means for the TPP negotiations «), lo que resultaría incomprensible si se piensa que es uno más de los 12 países involucrados, pero en el contexto del libro es bastante explicable. Es necesario tomar en cuenta su abismante poder de negociación frente a sus contrapartes (situación que sucede en realidad con sus ACRs), donde a 2011 el PIB de ese país, 57\% del conjunto de los 12 países, representando por sí solo más que la suma del resto de los restantes 11, incluyendo a Japón. Además, muchos de los temas que aparecen como principales puntos de conflicto en las negociaciones, como el incremento de los niveles de protección, tanto de los derechos de propiedad intelectual como de las inversiones o la inclusión de capítulos sobre aspectos laborales y de medio ambiente, corresponden precisamente a temas que impulsa Estados Unidos en sus negociaciones.

4 Australia, Corea del Sur, China, Japón, India y Nueva Zelanda 
El gran mérito del libro es que plantea preguntas, donde si bien pese a que las respuestas son bastante poco concluyentes, permiten que el lector llegue a sus propias reflexiones. La obra introduce de manera bastante clara un tema de por sí complejo, en parte por las distintas aristas que involucran las negociaciones del TPP y también porque incluye aspectos bastante técnicos, como las reglas de origen. Su lectura invita al debate, en un proceso que reviste singular importancia para países como Chile, que ha suscrito ACR con todos los países que integrarían la nueva asociación, y porque provoca dudas respecto de si los potenciales beneficios que obtendría el país compensan sus eventuales costos, como la posible renegociación de acuerdos suscritos anteriormente, en especialmente con los Estados Unidos.

Rodrigo Cuevas

Instituto de Estudios Internacionales 